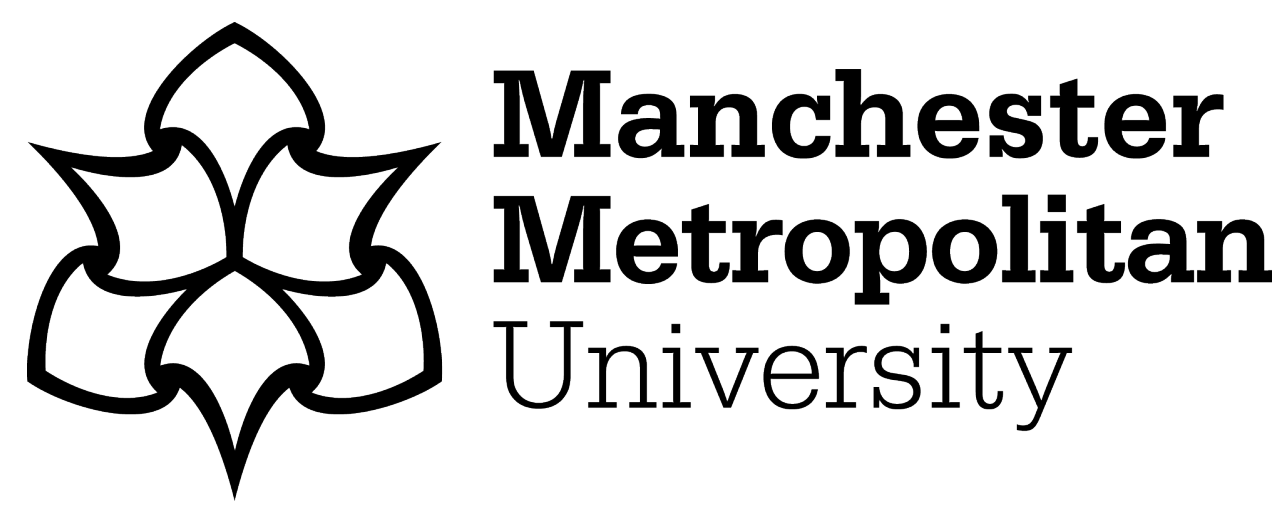

Perkin, SJ and Howe, PD (2018) A Foucauldian Interpretation of Paralympic Sport in the United Arab Emirates: An Exploration Through a Virtual Lens. International Journal of the History of Sport, 34 (13). pp. 1418-1435. ISSN 0952-3367

Downloaded from: https://e-space.mmu.ac.uk/622488/

Version: Accepted Version

Publisher: Taylor \& Francis

DOI: https://doi.org/10.1080/09523367.2018.1464441

Please cite the published version 


\title{
A Foucauldian Interpretation of Paralympic sport in the United Arab Emirates: an exploration through a virtual lens
}

\author{
Seth Joseph Perkin and P. David Howe \\ School of Sport, Exercise and Health Sciences \\ Loughborough University
}

\begin{abstract}
In this paper, we explore the interface between the construction of disability and the culture of the United Arab Emirates (UAE) with a focus on the implications that these have on the provision for Paralympic sport. Despite the previous literature that has investigated the relationship between sport and the Arab world, there is a significant void at the intersection between disability and sport within the Arab community. This paper uses a Foucauldian lens to unpack the relationship between the concepts of disability and Arab culture and how these are linked to Paralympic ethos. To achieve this aim, this paper uses virtual ethnographic methods. The internet is a flexible tool often understood as a cultural artefact which is socially constructed and a technology that was produced by particular people which contextually situated priorities. It is also a technology which is shaped by the ways in which it is marketed, taught and used. We believe the internet integrates with traditional cultures therefore providing a greater understanding and continual observation of Paralympic sport in the UAE.
\end{abstract}

Key Words: Disability; Foucault; Paralympics; United Arab Emirates

This paper explores the cultural landscape of the United Arab Emirates (UAE) and this nation's relationship with the conceptualization of disability and the implications these factors have on the provision for Parasport. In this paper, we define Parasport as the sport provision for people with disabilities based on the events at the Paralympic Games. We draw upon internet observations from January 2015 to September 2016. These observations came from mass media outlets and social media such as Facebook, Twitter and Instagram. Data were also collected using the websites from disability sport clubs, national sport federations, and the International Paralympic Committee (IPC).

Despite the previous literature that has investigated the relationship between sport and the Arab World, there has been a significant void at the intersection between disability and sport within the Arab community. ${ }^{1}$ The implications of this are acknowledged by Howe who asserts that the lack of research on Paralympic sport in non-Western contexts has led to ethnocentrism, where ideas around disability and disability sports studies are never explored from other cultural vantage points. ${ }^{2}$ In the last decade the oil rich nations of the Middle East including the UAE and Qatar have hosted a plethora of mega sporting events, challenging the Western dominance in organizing global sport and now these nations are looking to make a mark in the realm of Parasport.

The development of disability sport can be traced through three stages. ${ }^{3}$ The first stage is rooted in rehabilitative medicine and the inception of Stoke Mandeville Hospital in Aylesbury in the United Kingdom. The second stage of development that Howe alludes to is participation in disability sport. ${ }^{4}$ This can be seen in the creation of the Stoke Mandeville Games, which today is referred to as the 
Paralympic Games, coinciding with the third stage of development, high performance sport. The IPC was founded in 1989 and is based in Bonn, Germany. The quotation taken from the IPC website in explaining the Paralympic games states that it endeavours 'To enable Para athletes to achieve sporting excellence and inspire and excite the world'. ${ }^{5}$ Although the Paralympics is now an established force in global sport, these events adhere to a Western paradigm which often conflicts with non-western local cultures, and therefore, the intensification of staging global sporting events is potentially problematic. This can be viewed in the case of Qatar hosting the 2022 FIFA World Cup and the problems surrounding the consumption of alcohol during the tournament. ${ }^{6}$ Despite these tensions, the UAE has had involvement in the IPC since the Disability Sports Federation (DSF) was established as a national body by the government through ministerial decree in 1996, following on from the first UAE Paralympic team attending the 1992 Barcelona Paralympic Games. ${ }^{7}$ In the intervening years there has been a marked increase in the number of Paralympic events hosted by the UAE and this may have been instrumental in them sending the first female participant to the 2008 Beijing Paralympic Games. Since that time there has been an increase in UAE female participation and Rio de Janeiro in 2016 marked the first games where a female athlete won medals.

In what follows we use virtual ethnographic methods to explore the internet and social media to examine how the role of disability sport has been constructed in order to better understand its development in this distinctive cultural context. This paper starts by positioning the UAE in the global sporting arena. Following this we analyze the construction of disability both in the West, where the understanding of disability and its influence on sport originated, before moving onto exploring the literature on disability in the Arab world. We then detail the use of virtual ethnographic methods. Foucault's ideas are then discussed and their applicability to the topic sketched out before the online presence of Parasport in the UAE is deliberated. The paper concludes by highlighting potential future directions for research.

\section{The UAE and the Global Sporting Arena}

An article published online by BBC Sport highlights the emergence of the Gulf Countries in the new world sporting order. ${ }^{8}$ It posed the question whether Qatar and the UAE are the centre of the new sporting world. The new found dominance that can be attributed to the oil boom, which has resulted in dramatic and exponential development, has led to socio-economic conditions that are on par with the West. ${ }^{9}$ Perhaps, more importantly, the UAE has provided stability in the Middle East. As Fox et al. suggest, there has been no other part of the world that has seen such a rapid transformation than the oil states of the Arabian Gulf. ${ }^{10}$ Within two generations these areas have seen marked urban growth replace impoverished desert. This has led to an intensification of global sport and the Gulf States have seen an impressive haul of sporting events take place in the last decade, including golf, tennis, horse racing, motorsport, football, and rugby union sevens. ${ }^{11}$ This list is not exhaustive and there can be little doubt that the number of global sporting events will continue to grow. Amara suggests that at a state level, sport is a symbol of modernization in Muslim societies and allows for development as a tool for nation state building. ${ }^{12}$ This is clear to see in the UAE. The benefits of the global sporting arena have been noticed by Dubai's ruler Sheikh Mohammed bin Rashid al-Maktoum, who has stated that sport forms part of a multibillion-dollar charm offensive. ${ }^{13}$

There is some resistance to the promotion of professional sport in some quarters within the UAE,${ }^{14}$ yet there has been a marked increase in the development of disability and Paralympic sport within the region. This development of Paralympic sport has taken place in spite of negative attitudes towards those with disabilities. ${ }^{15}$ Dubai is now a staple feature on the IPC Athletics Grand Prix calendar, hosting the annual Fazza International Athletics Competition, where approximately 600 athletes from 45 different countries competed in the seventh edition of the event in 2016. Further international events in disability and Paralympic sport in the UAE have taken place. In 2011, Dubai and Sharjah hosted the International Wheelchair and Amputee Sport (IWAS), World Games, and IWAS World Junior Games, respectively. Dubai hosted the inaugural IPC Athletics Asia-Oceania championship in March 2016. In fact, there has been a significant investment into disability sport in the UAE in the last decade. Sheikh Mohammed Bin Rashid Al Maktoum invested \$1.63 million (AED\$6 million) into disability sport in 
the country, in order to improve participation at local, national, and international events. ${ }^{16}$ The development in hosting of events and the development of new facilities has occurred in spite of traditionally negative attitudes towards disabled populations in this nation.

\section{The Social Construction of Disability}

Disability and social discussions around the concept are important contemporary debates which have promoted an awareness of disability in a number of academic disciplines. ${ }^{17}$ The growing literature surrounding disability within sociology is marked by two distinctive bodies of research that have defined disability studies. ${ }^{18}$ These two approaches can be separated into a medical sociological approach that is 'informed by the idea that disability is caused by illness and impairment and entails suffering and some social disadvantage', and a social model of disability which explains the sociocultural factors that disable disabled people rather than their impairments. ${ }^{19}$ However, despite this intensification in the literature, the topic of disability within non-western contexts has received scant attention from the academic community.

At this juncture, a word of caution needs to be expressed regarding the previous literature surrounding disability. In discussing disability in the Arab World, the term 'disability' becomes problematic. The definition of disability, unlike disease, for instance, is relational to the social world that it is situated within; this for Topliss, makes it conceptually 'slippery'. ${ }^{20}$ Understandably, conceptualizing disability, therefore, is a difficult task. Firstly, according to Davis, the social implications of disability only appeared during the eighteenth and nineteenth century, with the onset of industrialization in the West, thus disability is framed heavily within a Western narrative. ${ }^{21}$ Therefore, implicit in the understanding of disability is the cultural make up of Western society and as a consequence the dissemination of attitudes towards disability. Miles states 'The dominant voices of European and North American debates on disability issues proceed with a common underpinning of (post)- Judaeo-Christian ethics and philosophy'. ${ }^{22}$ It may seem paradoxical that Judaism and Christianity shape discussions of disability in the ever increasing secular West. Miles argues that global conversations regarding impairment, viewed from outside the West, demonstrate the religious underpinnings of Western culture. ${ }^{23}$ There may be some surprise from secularist Westerners, that their core key assumptions, norms, and values have been subconsciously permeated by religious doctrine. Nonetheless, as Davie notes, while within Britain there has been a clear separation between some groups in society with institutional Christianity, there still remains a belief in religious thought without the associated practice. ${ }^{24}$ The implications for this are clear. The majority of discussions that have previously taken place regarding disability have been shaped by religious understanding and scripture, since the construction of disability at its point of origin is shaped by Western religious ideology. While this has had implications in academic literature, it also can be viewed in wider society. ${ }^{25}$ Coll and Magnuson note a 'cultural mismatch', when service programmes are initiated where the service provider's perceptions of disability are different to those of the local culture. ${ }^{26}$ As Diken suggests, there needs to be an increased dialogue and understanding between cross cultural groups surrounding beliefs of disability, ${ }^{27}$ a common feature of research that has been conducted on the Arab world. ${ }^{28}$

Despite the Western bias of the literature on disability, it is important that this is the point of departure when understanding disability in other cultural contexts. The study of disability has previously been seen as a neglected topic within mainstream sociology. ${ }^{29}$ Ever increasing dissatisfaction surrounding social rights for people with a disability led to the growth of the disability movement, which first gained momentum during the latter part of the twentieth century in Britain and the rest of the developed world. ${ }^{30}$ The growing awareness of disability in society can be attributed to other social movements that have pursued equality, namely feminism and to a certain extent Lesbian Gay Bisexual Transgender (LGBT). Despite the literature on disability still being in its relative infancy, it has seen an increased awareness of the rights of the disabled and a promotion of those with disabilities. However, this increased 'awareness' of disability has not always been translated into positive results for those with disabilities. 
In following other social movements, it also raises questions of cross cultural application in the efficacy of using such movements to improve disability rights in countries with different paradigmatic approaches.

\section{Disability in The UAE}

To date research on disability has been limited in the UAE, and the Arab World as a whole. Due to the majority of incidences of disability taking place in different cultural contexts, that do not share commonality with Western ethics and philosophy, this for Miles has perpetuated unfamiliar terms of disability for many in the West that has allowed and continues to allow the creation of stereotypes. ${ }^{31}$ In Arab culture the study of disability is still in its infancy and the questionable validity of statistical evidence and the differing methodological approaches used across the region to investigate disability appear to be part of the problem. ${ }^{32}$ Gharaibeh states, that despite the limited and unreliability of statistical recording within the Arab region, the evidence suggests that due to the culture itself contributing to higher level rates of disability, the prevalence of disability should be estimated to be higher within the region in comparison to Europe and North America. ${ }^{33}$

The prevalence of consanguineous marriages and in particular marriages to first cousins is particularly high within the Arab World and may be one reason for a higher percentage of disability. ${ }^{34}$ First cousin marriages in the UAE equate to $30 \%$ of all marriages. Consanguineous marriages, alongside mothers giving birth into their forties and with cultural, legal, and religious limitations on prevention and control of genetic disorders, means that a high proportion of infants are born with a congenital illness; 'causing either mortality, morbidity, and handicap in Arab countries'.$^{35}$ With higher levels of congenital illness in the UAE and the Gulf region as a whole, this has seen an increased promotion and participation in the participatory based event for those with an intellectual disability - The Special Olympics. The Special Olympics aims to provide a normative way of life for those with intellectual disabilities through the vehicle of sport, ${ }^{36}$ while the Paralympics' initial focus was placed on rehabilitation. However, developments within the Paralympic movement has seen the emphasis firmly grounded in high performance sport, mirroring the Olympics. ${ }^{37}$

The perceptions of disability are mixed within the UAE. In the studies that have analysed the attitudes surrounding both intellectual and physical disability in the UAE in mainstream education, ${ }^{38}$ physical and intellectual disabilities in the workplace, ${ }^{39}$ and social inclusion and the subsequent responses of the families, ${ }^{40}$ similar results on attitudes with disability within the last 15 years have been found. Alghazo and Gaad report, that within education in the UAE, there are generally negative attitudes surrounding students with disabilities in mainstream education..$^{41}$ Gaad has also found that some teachers in the UAE hold cultural beliefs that the best place for students is disability centres. ${ }^{42}$ However, this is not a problem limited to the UAE, as there is historical evidence to suggest that within the education system in Western countries, the inclusion of those with intellectual disabilities is made more difficult by a teacher's reluctance to have these individuals within their classrooms. ${ }^{43}$ Alborno and Gaad note, that within the workplace employment of those with a disability was seen as an act of charity rather than a right. ${ }^{44}$ There is a social stigma placed upon those with disabilities and the previous examples are supported by the work of Crabtree, who states that the home is seen as the most appropriate domain for adult female daughters and young children with disabilities. ${ }^{45}$ It is important to state at this juncture that Islam does not discriminate against those with disabilities and teaches that care should be extended to those who have a disability. ${ }^{46}$

Islam responds positively towards disability and this can be traced to Qur'anic and Hadith teachings on disability and the prevalence of disability within the Ottoman Empire. There have been disagreements within the academic world with regards to the role of Islam, the Quran, the Hadith and the impact that they have had in creating acceptance within a society mostly devoid of stigmatization. As Asad states 'as long as we have to do with human, biologically limited beings, we cannot possibly consider the idea 
of absolute perfection, because everything absolute belongs to the realm of Divine attributes alone' ${ }^{47}$ Barnnart and Kabzems have found that attitudes towards disability are flexible depending on the severity of the disability. ${ }^{48}$ However, evidence has been put forward by Turmusani who states that those who have a disability suffer socially and economically. ${ }^{49}$

The Syrian scholar Sa' dī Abū Jayb, cited in Ghaly, formulated the argument that within Sufi Islamic culture there are two main differences between disability. These differences can be defined as ostensible (zāhira) disability and real (haquiqiyya) disability. ${ }^{50}$ Abū Jayb defines ostensible disability as the affliction of the body and real disability transpires in the soul and in turn affects the relationship with God. Thus, within Islam real disability has the ability, rather than ostensible disability, to cause harm to one's status and dignity. ${ }^{51}$ There is no explicit link between Islam and the attitudes shown towards disability, it is rather a case of Arab culture. ${ }^{52}$ Undertaking a historical analysis of the role of disability within the Ottoman Empire, Scalenghe documents the occurrence of disability in the literature. ${ }^{53}$ Through this analysis, Scalenghe observes that due to the frequency of disability within the Ottoman Empire, there was reduced discrimination against those with impairments. ${ }^{54}$ With a distinctive cultural understanding of disability, we turn to how the internet and social media may be used as a virtual ethnographic tool to make sense of disability sport in the UAE.

\section{Virtual Ethnography}

In similar ways to more traditional ethnographies there is no definitive methodological approach that defines virtual ethnography; ${ }^{55}$ rather as O'Reilly notes, it is a family of methods. ${ }^{56}$ There is a growing movement within sociology and anthropology in using the internet as a field to collect data. Hammersley and Atkinson state that 'Digital technology has expanded our very notion of what constitutes a "field". Virtual fields and fieldwork are now possible'.... ${ }^{57}$ This has allowed for virtual ethnography to be possible. Hine highlights the different ways that the internet can be viewed. ${ }^{58}$ One way of viewing the internet is that it is a cultural artefact, and for Woolgar, this sees the internet as socially constructed and a technology that was produced by particular people which contextually situated goals and priorities. ${ }^{59} \mathrm{It}$ is also a technology which is shaped by the ways in which it is marketed taught and used. As Castells notes, 'new electronic media do not depart from traditional cultures: they absorb them' ${ }^{60}$ The internet has now manifested itself into, what is for many, an essential part of daily life. What was once considered its own dedicated activity, Hine notes that this is now replaced by catching up with friends using social media rather than going on the internet. ${ }^{61}$ It should be taken into consideration that even the literature that has been produced in the last couple of years can be considered outdated.

Reducing the internet to its most basic level, it allows for information to be transmitted from one computer to another. ${ }^{62}$ Technology such as the internet and other similar networks provide 'a naturally occurring field site' that allows for research to be conducted on certain peoples' online habits. ${ }^{63}$ The internet or other digital technologies has no universal definition. Miller and Horst note that society has different definitions for digital. ${ }^{64}$ Therefore, for simplicity digital is everything that has been developed and can be reduced to binary. ${ }^{65}$ Unsurprisingly the ambiguity in defining the internet or digital brings up one of the most fundamental issues in using the internet as a research field. The social importance of the internet and how it is used cross culturally is of increasing interest to social scientific researchers. As Hine states, regarding the internet and the way it is viewed 'we should not necessarily expect it to mean the same thing to everyone'. It could be said that ideas about what the internet is are socially shaped, in that they arise in contexts of use in which different ways of viewing the technology are meaningful and acceptable. ${ }^{66}$

\section{Methodology}

To form an understanding of Parasport within the UAE, internet research was conducted between January 2015 and September 2016. Data were collected from both mainstream media sources and social 
media accounts that were based within the UAE, alongside the IPC website. While this forms a significant time period, it should be not considered that this resulted in a wide range of data collected. Within the mainstream media, articles relating to Parasport and disability sport during the collection of data were sparse; the implications of this will be discussed in greater detail later. In order to collect data through the mainstream media, key phrases such as 'disability', 'Paralympics', and 'disability sport' were used in order to find relevant articles in order to plot the cultural landscape of Parasport. Social media accounts such as Facebook, Twitter, Instagram and the websites of disability services, disability sports clubs, and the disability sports federation were also visited twice a week.

The social construction of the internet is immersed within the local offline culture. As Pink et al. write, social worlds intersect with each other and are not bound by walls that clearly define themselves ${ }^{67}$ This can be argued further that with the invention of technology and how readily accessible the internet is our lives are a blend of offline and online cultures. ${ }^{68}$ The importance of social media should not be underestimated since social media at present has an even greater influence on the offline world than mass media outlets in contemporary society. The development of the internet has facilitated the ever increasing significance of social media in daily life, allowing for greater personalization in civic engagement keeping us more engaged, unlike previous forms of mass media ${ }^{69}$ The number of internet users in the UAE in June 2016 was just over 8.5 million, which equates to $91.9 \%$ of the population having access and using the internet regularly, while over 7.5 million Emirati nationals are registered with Facebook, which equates to $83.1 \%$ of the population. ${ }^{70}$ Using social media brings its own unique challenges to the research that differ from using mainstream media sources and more traditional ethnographic methods. In their paper on Twitter, Marwick and boyd argue that using this type of social media brings forward issues of representation. ${ }^{71}$ They state "We may understand that the Twitter or Facebook audience is potentially limitless, but we often act as if it were bounded' ${ }^{72}$ This is to say that despite the potential engagement that Twitter and other social media outlets possess, the posts are written with an 'imagined audience' in mind and in doing so frames any interaction heavily within the author's cultural context and will therefore be unfamiliar to the 'actual' audience. Keeping these issues in mind we now turn our attention to the use of a Foucauldian lens as central to a virtual ethnographic analysis.

\section{Using Foucault in Virtual Ethnography}

Despite Foucault writing before the invention of the internet, his work is increasingly relevant in understanding the internet with regards to Jeremy Bentham's panopticon, that Foucault makes frequent reference to in Discipline and Punish. ${ }^{73}$ The panopticon isolated each 'inmate' in their own separate cells, while being available to be viewed from a central point. Panopticism imposes a continual visibility on the most elementary facets of life, ${ }^{74}$ and Foucault notes that this perfect disciplinary technology can allow for a single gaze to monitor constantly. ${ }^{75}$ 'A central point would be both the source of light illuminating everything, a locus of convergence for everything that must be known: a perfect eye that nothing would escape' ${ }^{76}$ During the eighteenth and nineteenth centuries, Foucault argues that there had been a shift in the architecture of society; moving from visible to socially constructed boundaries. Through the use of the panopticon, the inmates (or whoever is under the gaze) develop 'an impersonal and anonymous relationship with power' ${ }^{77}$ The inmate's behaviours alter due to the presence of the continual gaze of authority, despite the fact they may or may not be watching. However, as this cannot be confirmed by the inmates, they act as if they are under constant surveillance; discipline becomes self-regulatory. Foucault uses the architecture of the panopticon and expands it to the broader social context, ${ }^{78}$ and states that modern society is 'a disciplinary society' ${ }^{79}$ This disciplinary society can be extended into the hyper mediated global culture that is a staple feature of today's modern world.

Using the concepts of Foucauldian analysis, we can theorize the connection between religion and disability within a Western setting and the comparisons that can be drawn with disability in the UAE. When understanding disability, the analogy of the panopticon can be utilized. This analogy of the panopticon has been transported from the 'penal institutions to the entire social body'. ${ }^{80}$ The normalizing gaze of the panopticon, produces subjectivity and self-control to keep bodies docile, in 
order to fit in with society. It is only when there is an abnormality within society that we notice the gaze. Therefore, in a similar way the relationship with power is altered, resulting in the self-regulation of bodies. Over the course of history there have been repeated examples of isolating members of society that cause a threat to normal order. Foucault highlights this happening through numerous examples such as the isolation of lepers and what is described as 'the great confinement' that can be dated to 1656 that established the Hôpital Général in Paris. ${ }^{81}$ Furthermore, during the nineteenth and twentieth centuries modern psychiatry was born and made its way into hospitals and prisons alongside the stigmatization, medicalization, and the normalization of sexual deviance in Europe ${ }^{82}$ Through these examples stated above 'the subject is objectified by a process of division either within himself or from others' ${ }^{83}$ Through categorization and social objectification, it gives a social and a personal identity to an individual. Rabinow states these "dividing practices" are modes of manipulation that combine the mediation of a science (or pseudo-science) and the practice of exclusion - usually in a spatial sense, but always in a social one' ${ }^{84}$ With the gaze of the panopticon determined by societal norms and values, the body is subjected to forces controlled and manipulated by those in power, which in this case is the government of the UAE. With the governments increased interest and investment into sport, it has arguably changed the panoptical gaze.

\section{Discussion: Unpacking the Virtual World with Foucault}

In unpacking the cultural landscape of disability sport within the UAE, there needs firstly to be an understanding of the discourse surrounding disability. Through observations of mainstream media there has been an increase in the promotion of disability rights in the last decade, in order to reconstruct the UAE as a nation which integrates the disability community which has been previously isolated into wider society. ${ }^{85}$ An example of this can be seen in article published in the National which reports that an advocacy group in the UAE is still tackling problems that people with disabilities face on a regular basis. As one of the group founders state 'Most disabled people feel shame. Some are even shy to even meet family members ... ${ }^{86}$ To counteract this and to improve disability rights, initiatives such as 'My Community' have been set up, in which The Crown Prince of Dubai Sheikh Hamdan bin Mohammed bin Rashid Al Maktoum is heavily involved with the project. This is significant in that 'My Community' states its aims are 'turning Dubai into an inclusive, barrier-free, rights-based society that promotes, protects and ensures the self-determination of persons with disabilities' ${ }^{87}$ With My Community providing a wide range of services from healthcare to providing education, employment opportunities while increasing accessibility and social benefits, this can be explained using Foucault's notion of 'Biopower' ${ }^{88}$ It should be of no surprise that the number of services that My Community deliver within Dubai feature across all facets of society, each producing their own disciplinary powers and normalizing judgements through government directives in order to keep 'disabled bodies' docile and produce an efficient body. With this as the point of departure, the construction of disability sport can be analyzed.

Since Qatar was awarded the right to host the FIFA World Cup in 2022, the oil rich nations of the Gulf have been in the world's spotlight with their increasing desire to hold the globe's showcase sporting events. While the UAE has not yet officially bid for the Olympic Games and subsequently the Paralympic Games, there have been a number of statements of intent to host both Games in Dubai. ${ }^{89}$ The potential impact of the UAE hosting the Olympics and Paralympics would undoubtedly strengthen the position of the Emirates within world sport. This has the potential to benefit the Paralympic movement in the UAE. Clubs such as the Dubai Club for the Disabled have benefited from royal patronage, and the Fazza Championships for the disabled are held annually by the Dubai Club as per the directives of the Sheikh Hamdan bin Mohammed bin Rashid Al Maktoum, who holds an active interest in able-bodied and disability sport. ${ }^{90}$ Of course, in the Arab World, as Amara points out, there are numerous incidences where Arab Presidents and Kings have presented trophies to the nation's sporting clubs and athletes. ${ }^{91}$ The association of such high profile figures gives the Dubai Club for the Disabled a significantly improved presence in the virtual world, which it would have unlikely achieved without this patronage. The significance and emergence in the disability sporting world can be linked to the social and economic history of the UAE and its reluctance to invest in single economic interests due to the previous sole focus on pearl diving and the economic consequences that followed. ${ }^{92}$ The 
investment into sporting opportunities for the disabled as highlighted in the virtual landscape can been seen through the lens of Foucault as a direct response to the need to be treating traditionally marginalized populations in an equitable way. In other words, the 'eyes of the world' are acting like a panopticon.

This raises the question whether the UAE as a country is ultimately looking to progress its national sport teams in the Olympics and Paralympics or whether these ventures into elite global sport are a form of investment to maintain the infrastructure to hold the Olympic and Paralympic games - bringing money to the nation by pleasing the West's watchful eye. If the Paralympics are compared with the Olympic movement in the UAE, there are similarities that can be drawn with the presence of both movements on the global stage. One bronze medal was secured in judo during the Rio 2016 Olympic Games for the UAE, only the country's second Olympic medal after securing gold at Athens in 2004 in the men's double trap shooting event. The Paralympic teams on the other hand have secured a higher number of medals since their first medal in Sydney at the 2000 games. While the medal haul by the UAE is relatively high in the Paralympics, certainly in comparison to other countries within the Arabian Gulf, the provision for Parasport and able bodied sport such as the Olympics and local professional sports teams has a reduced presence online. Further comparisons can be made with their online presence, as the Paralympic movement receives less attention than their Olympic counterparts. Although this is not exclusive to the UAE, this is a trend that is also seen in the West.

In the run up to Rio 2016, the coverage of Olympic and Paralympic sport was limited and the news stories focussed on global sporting events. This is highlighted in a field note extract from August 2016, taken in relation to the National website, an English-speaking newspaper based in the UAE:

The traditional, familiar look of a Western online newspaper greets me as I click onto the homepage of The National. A welcome omission is the lack of articles on celebrity culture being the only noticeable difference between The National and any other Western newspaper. Featured on the homepage is an article about the US fencer Ibtihaj Muhammad's goal during the Olympics to change the perceived ideology about Muslim women in Rio. Clicking back to the sport homepage the more familiar news stories of the English Premier League are heavily featured, the instantly recognizable club shirts of Manchester City with their title sponsors Etihad Airways feature heavily in the title story. Formula 1, cricket, more stories about the English Premier League, Lionel Messi, Italian Serie A, unsurprising given the involvement of the United Arab Emirates in global sport. The colours of the Emirates flag superimposed onto the image of the athletes that will be competing in Rio announces 'Meet the men and women representing the UAE at the Olympics' before opening a profile page on each athlete. The lack of news stories on the Paralympics starts to become apparent, apart from mentions of [the] Oscar Pistorus court case, there is only a sporadic mention of the upcoming Paralympics which will be held in the following month. A search of 'Paralympics' reveals sixteen articles have been published since January 2015 and only five of those articles focus on Emirati nationals. Articles on the Fazza International Championships are dominated by images of foreign athletes proudly representing their country in competition. Rehabilitation and participation is a recurring theme in the articles focusing on the Emirati nationals.

The main theme that comes through this observation is that this publication, and a number of other publications based in the UAE, are written in English and mirror publications found in Britain. In some quarters of the UAE there is now concern with the prevalence of English throughout the Emirates, and the influence it has in fostering departures from Arab culture and Arabic. ${ }^{93}$ The use of English is, however, seen as necessary in response to the rapid development that has taken place in the region. ${ }^{94}$ It is the language at the centre of the Western-oriented panopticon. This in part provides an explanation for the dominating images of European and global sport that were continually observed throughout data collection. With over 7.8 million expatriates in the region compared to that of just over 1 million local Emirati nationals, the online world is following the template set by the offline world. ${ }^{95}$ As Amara notes, 
the development of cricket within Abu Dhabi, Sharjah, and Dubai is in response to a population of expatriates from the Indian subcontinent, ${ }^{96}$ providing just one example of the integration of the online/offline worlds.

With the local population being in the minority and the Emirates investment in global sport providing the main points of interest in the media, Olympic and Paralympic sport inhabit a problematic space within the UAE. This is a trend not limited to the Olympic and Paralympic websites themselves but is rather symptomatic of sport in the UAE as a whole. The lack of attention to Paralympic sport is not limited to one online newspaper, as investigation of the other English-speaking media sources provided similar results. The images that appeared in the articles on Paralympic sport tended to show international athletes competing rather than Emirati nationals and when images of local athletes were published the athletes were not featured in competition. There also seems to be a lack of interest in the Olympic Movement within the UAE. Both the National Olympic Committee and the (DSF) websites provide limited information and this further raises the issue of whether these teams are put in place to allow for an Olympic and Paralympic bid to be put forward. Clearly, there is an idea that having an outward facing website is of paramount importance, but while the Western gaze acknowledges this to some extent the UAE sports community has 'drawn the blinds' on internal detail.

Participation by local athletes within the Paralympics and Parasport is good within the UAE, but the online presence is very limited. As previously stated, with such high internet usage figures reported in the region, there is vast potential for promoting Parasport, however at present Paralympic sport features in an extremely small minority of the published articles. This is a critique not limited to the UAE, as similar trends can be observed in the West. There is, however, a need to address the official websites of the Paralympic Committee. Historically, the UAE has been without a National Paralympic Committee website and it is only recently that one has been put online. To serve in its place while there was no official Paralympic committee website, the UAE DSF was used. Both websites offer rather primitive and narrow insights into Parasport within the region. This is also similar to the six disability sports club in the region. These factors, alongside the small population of Emirati locals, sees the focus of Parasport within the UAE heavily framed within rehabilitation, thus mirroring early developments of disability sport that took place in Stoke Mandeville Hospital after the Second World War. ${ }^{97}$ This is highlighted by one of the disability sports club in the UAE and its focus on a 'holistic' approach to disability. The images that feature on the Dubai Club for the Disabled social media pages emphasizes the social role of the club and the club's engagement in wider society. Photographs of Parasport are limited to recreational activities or activities taking place during international competitions hosted by the club. A Foucauldian view of this would argue that this heavy focus on rehabilitation is to make disabled bodies 'docile'. The institutions that manage disabled bodies incorporate these acts by making those with disabilities appear as subjects. The club, funded by the government, provides observation over its members with disabilities and normalizes the behaviours of its members through 'correct training' techniques. ${ }^{98}$ Therefore, the end goal is to rehabilitate people with disabilities to be functional members of society.

This perspective should not be viewed as a critique of Parasport and the Paralympic Committee within the region but rather a reflection of Parasport being in its relative infancy. While the UAE National Paralympic Committee's objectives highlight the continued involvement in the Paralympic Games and other competitions within the region, the main objective is to 'Sponsor and develop the sport of the disabled in the country and to introduce the public to the sports of the handicapped' ${ }^{99}$ This objective is made difficult through the lack of media engagement both in the mass media and also by the disability sports clubs within the region, in part because there are only two clubs that have an active presence on social media. With there still being some stigma attached to disability within the region, the media has proved an important vehicle in changing the discourse of the most prevalent disabilities, which are intellectual. ${ }^{100}$

Social media in the lead up to the Paralympic games in Rio has seen a marked increase in the production of images and videos to promote the UAE national Paralympic team. The recurring headline on the 
pictures of the athletes on the UAE DSF Facebook page is 'Impossible is not in the dictionary'. Similar themes can be seen within other social media pages. For example, the Sharjah City for Humantarian Services have posted images with captions such as 'Find an excuse to win' and 'We wish success to our heroes', interspersed between pictures of recreational and social activities. Similarities can be drawn with discourses of Paralympians in Britain that encourage the 'Supercrip' ideology. Using Silva and Howe's definition of supercrip as a stereotype where someone achieves success despite their impairment, ${ }^{101}$ this constructs a problematic nature of disability in the UAE in much the same way it has in the West. Yet there are articles published online to promote Dubai's vision of being one of the world's most disability-friendly cities in time for the World Expo in 2020. ${ }^{102}$ While the internet presence of Parasport is limited, the promotion of disability through articles related to the promotion of disability rights, the upcoming Expo 2020 and creating a disability-friendly city, manipulate the understandings of disability and the role of those with disabilities in UAE society.

\section{Conclusion}

There is often criticism levelled at the Arab World for its record within Paralympic sport and the broader social context of disability by commentators in the West. While negative attitudes are still present within general society in the UAE, ${ }^{103}$ the growing number of foundations and charities within the UAE and their online presence within the region is inevitably shaping the social construction of disability. In regard to the Paralympic movement, what is apparent, however, is that the UAE is still in its relative infancy. As a result, there are still a number of issues that are not uncommon to disability sport within the West. Moreover, the UAE focus on Parasport is limited by the population of Emirati nationals, for despite a population of over 9 million, there are only approximately 900,000 nationals within the UAE. Therefore, there is not a great deal of potential Paralympians, and with a focus primarily at this stage heavily framed on the rehabilitation element of disability sport, growth in the area is behind that of the West.

Within the UAE, the media had a significant influence in creating a marked change in the perception of intellectual disabilities. This change was not limited to the individual themselves but also included families. In turn, this prompted increased inclusivity within mainstream education. ${ }^{104}$ Therefore, for Gaad, the power of the media should not be underestimated as a vehicle for changes and there should be an increased presence of the promotion of disability inclusion within UAE society. ${ }^{105}$ The presence in the mass media was limited in regard to articles on Parasport and the Paralympics. An issue with more concern is that similar trends can also be observed in the clubs' own social media presence. Despite the fact that there are six clubs in the country, only two clubs had an active presence on social media. Nonetheless the social media pages of these clubs were regularly updated and served to publicize the club and educate Emirati society about disability. Clearly the role of social media needs to be more widely utilized within the UAE, not only to change the perceptions of disability but to generate wider interest in Parasport as a whole within the region. With such vast investment in global sporting events that feature heavily and daily online, Parasport faces a difficult challenge in generating and maintaining interest within the UAE, where a diverse range of sporting events are regularly featured. Despite the success of the UAE Paralympic team, which have regularly outperformed their Olympic counterparts in terms of medals won, interest in Parasport is limited. However, the Paralympics is a difficult sporting event to market, as observed with the problems that faced the organizers of the Paralympics games in Rio, where there was a lack of public

interest.

While using the internet as a research site has provided an exploratory analysis of Parasport within the UAE, using a virtual ethnography and the internet creates issues such as the validity and authenticity of the research. A key question in this debate focuses on how a virtual sphere of existence can hold truth within the 'real world'. ${ }^{106}$ Digital technologies and the internet can provide anonymity and allow for an adoption of a different personae. However, there is no guarantee that online identities will match their offline counterparts. ${ }^{107}$ In fact, given the anonymity the internet provides, it can allow for a deliberate 
exploration of different identities. ${ }^{108}$ Positives and negatives can be drawn from this. While this may provide data that is unattainable 'offline', there are numerous examples within the internet of people masquerading as someone else online, highlighting the problematic nature of authenticating identities online and the authenticity of internet research. ${ }^{109}$ This is important to take into consideration when exploring the issue of disability sport within the UAE. With the West forming the panoptic gaze over the UAE, it is therefore unlikely that a country that has a significant economic investment in the West will publish articles that highlight cultural ambiguities in the construction of disability between the Arab world and the West. It is therefore difficult to distinguish how online practices dictate offline practices. However, it can be said with confidence that the online world is a reflection of its offline counterpart.

This paper forms the initial discussion and signals future directions of work, in which offline practices form the basis of the discussion. Other directions of research also include the female Paralympic athlete and Parasport athletes within the UAE. There was, for instance, a noticeable lack of female Para athletes featured in competition by both the mass media and social media. This broadly follows the trend of Arab women in sport being in the minority. However, the UAE is at the forefront of challenging the resistance and social barriers that are often found in women's participation in sport within the region. ${ }^{110}$

\section{References}

1. Mahfoud Amara, '2006 Qatar Asian Games: A “Modernization” Project from Above?', Sport in Society 8, no. 3 (2005), 495-516; Mahfoud Amara, 'When the Arab World was Mobilized Around the FIFA 2006 World Cup', Jounal of North African Studies 12, no. 4 (2007), 417- 38; Mahfoud Amara, Sport, Politics and Society in the Arab World (Basingstoke: Palgrave Macmillan, 2012); Ian Henry, Mahfoud Amara and Mansour Al-Tauqi, 'Sport, Arab Nationalism and the Pan-Arab Games', International Review for the Sociology of Sport 38, no. 3 (2003), 295-310; John Sugden, 'Teaching and Playing Sport for Conflict Resolution and Coexistence in Israel', International Review for the Sociology of Sport 41, no. 2 (2006), 221-40; and Geoffrey Whitfield, Amity in the Middle East: How the World Sports Peace Project and the Passion for Football Brought Together Arab and Jewish Youngsters (London: Alpha Press 2006).

${ }^{2}$ P. David Howe, The Cultural Politics of the Paralympic Movement: Through an Anthropological Lens (Oxon: Routledge, 2008).

${ }^{3}$ Ibid

${ }^{4}$ Ibid

5 International Paralympic Committee, 'Paralympic Vision and Mission, IPC Handbook April 2003', https://www.paralympic.org/sites/default/files/document/120203111830492_Sec_i_chapter_1.1_Paralympic_Vi sion_and_Mission_0.pdf (accessed 1 September 2016).

${ }^{6}$ Susan Dun, 'No Beer, No Way! Football Fan Identity Enactment Won't Mix with Muslim Beliefs in the Qatar 2022 World Cup', Journal of Policy Research in Tourism, Leisure and Events 6, no. 2 (2014), 186-99.

${ }^{7}$ United Arab Emirates Disability Sports Federation, 'Volition Knights UAE Disable Sports Federation 20092010', http://www.uaedsf.ae/\#our-magazine (accessed 3 October 2016)

${ }^{8}$ Ben Smith, 'Qatar, Abu Dhabi and Dubai: New Centre for the Sporting World?', BBC Sport, 25 November 2014, http://www.bbc.co.uk/sport/football/30180206 (accessed 1 August 2016).

${ }^{9}$ Christopher M. Davidson, The United Arab Emirates: A Study in Survival (London: Lynne Rienner, 2005).

${ }^{10}$ John W. Fox, Nada Mourtada-Sabbah and Mohammed al-Mutawa, 'The Arab Gulf Region:Traditionalism Globalized or Globalization Traditionalized?', in John W. Fox, Nada Mourtada-Sabbah and Mohammed alMutawa (eds), Globalization and the Gulf (Oxon: Routledge,2006), 3-61.

${ }^{11}$ Steven J. Jackson and Stephen Haigh, 'Between and Beyond Politics: Sport and Foreign Policy in a Globalizing World', Sport in Society 11, no. 4 (2008), 349-58.

12 Amara, Sport Politics and Society in the Arab World.

13 'Spoil Sports', Guardian, 11 November 2007, https://www.theguardian.com/sport/blog/2007/nov/11/spoilsports (accessed 1 August 2016).

${ }^{14}$ Amara, Sport Politics and Society in the Arab World. 
${ }^{15}$ James Reinl, 'Arab Region “Lacks” Disability Awareness', National, 3 September 2008, http://www.thenational.ae/news/world/middle-east/arab-region-lacks-disability-awareness (accessed 26 January 2017).

${ }^{16}$ IWAS, 'Disability Sport in the UAE to Receive Financial Boost',

http://www.iwasf.com/iwasf/index.cfm/iwas-news/disability-sport-in-the-uae-to-receive-financial-boost (accessed 12 September 2016).

${ }^{17}$ Michael Oliver and Colin Barnes, The New Politics of Disablement (London: Macmillan, 2012)

${ }^{18}$ Carol Thomas, 'How is Disability Understood? An Examination of Sociological Approaches', Disability and Society 19, no. 6 (2004), 569-83.

${ }^{19}$ Ibid., 570.

${ }^{20}$ Eda Topliss, Provision for the Disabled, 2nd ed. (Oxford: Blackwell, 1979).

${ }^{21}$ Lennard J. Davis, Enforcing Normalcy: Disability, Deafness and the Body (London: Verso, 1995).

${ }^{22}$ M. Miles, 'Disability in an Eastern Religious Context: Historical Perspectives', Disability \& Society 10, no. 1 (1995), 49-69.

${ }^{23} \mathrm{Ibid}$

${ }^{24}$ Grace Davie, Religion in Britain Since 1945: Believing Without Belonging (Making Contemporary Britain)

(Oxford: Blackwell, 1994).

${ }^{25}$ Edward Said, Orientalism: Western Conceptions of the Orient (Hammondsworth: Penguin, 1995).

${ }^{26}$ Cynthia García Coll and Katherine Magnuson, 'Cultural Differences as Sources of Developmental Vulnerabilities and Resources', in Jack P. Shonkoff and Samuel J. Meisels (eds), Handbook of Early Childhood Intervention (Cambridge: Cambridge University Press, 2006), 90.

${ }^{27}$ Ibahim H. Diken, 'Review of Research: An Overview of Parental Perceptions in Cross-Cultural Groups on Disability', Childhood Education 82, no. 4 (2006), 236-40.

${ }^{28}$ Edward Said, Orientalism.

${ }^{29}$ Susan Reynolds Whyte and Benedicte Ingstad, 'Disability and Culture: An Overview', in Benedicte Ingstad and Susan Reynolds Whyte (eds), Disability and Culture (Berkeley: University of California Press, 1995), 3-35.

${ }^{30}$ Bill Hughes and Kevin Paterson, 'The Social Model of Disability and the Disappearing Body: Towards a Sociology of Impairment', Disability \& Society 12, no. 3 (1997), 325-40; Michael Oliver, The Politics of Disablement (Basingstoke: Palgrave Macmillan, 1997); Tom W. Shakespeare, Disability Rights and Wrongs (London: Routledge, 2006); and Bryan S. Turner, 'Disability and the Sociology of the Body', in Gary L. Alberecht, Katherine D. Seelman and Michael Bury (eds), Handbook of Disability Studies (Thousand Oaks: California, 2001), 252-66.

${ }^{31}$ Miles, 'Disability in an Eastern Religious Context'.

${ }^{32}$ Numan Gharaibeh, 'Disability in Arab Societies', in Catherine A. Marshall (ed.), Disabilities: Insights from Across Fields and Around the World (Westport: Praeger, 2009), 63-81.

${ }^{33}$ Ibid.

${ }^{34}$ Lihadh Al-Gazali, Hanan Hamamy and Shaikha Al-Arrayad, 'Genetic Disorders in the Arab World', BMJ 333 (2006), 831

${ }^{35}$ Ibid., 831.

${ }^{36}$ Coreen M. Harda et al., 'Promoting Social Inclusion for People with Intellectual Disabilities Through Sport: Special Olympics International, Global Sport Initiatives and Strategies', Sport in Society 14, no. 9 (2011), 113148.

${ }^{37}$ Howe, The Cultural Politics of the Paralympic Movement.

${ }^{38}$ Emad M. Alghazo and Eman Gaad, 'General Education Teachers in the United Arab Emirates and Their Acceptance of the Inclusion of Students with Disabilities', British Journal of Special Education 31, no. 2 (2004), 94 9; Eman Gaad, 'Educating Children with Down's Syndrome in the United Arab Emirates', British Journal of Special Education 28, no. 4 (2001), 195-203; Eman Gaad, 'Cross-Cultural Perspectives on the Effect of Cultural Attitudes Towards Inclusion for Children with Intellectual Disabilities', International Journal of Inclusive Education 8, no. 3 (2004), 311-28; and Eman Gaad, 'The Social and Educational Impacts of the First National Down Syndrome Support Group in the UAE', Journal of Research in Special Educational Needs 6, no. 3 (2006), 134-42.

${ }^{39}$ Nadera Alboro and Eman Gaad, 'Employment of Young Adults with Disabilities in Dubai: A Case Study', Journal of Policy and Practice in Intellectual Disabilities 9, no. 2 (2012), 103-11.

${ }^{40}$ Sara Ashencaen Crabtree, 'Maternal Perceptions of Care-Giving of Children with Developmental Disabilities in the United Arab Emirates', Journal of Applied Research in Intellectual Disabilities 20 (2006), 247-55.

${ }^{41}$ Alghazo and Gaad, 'General Education Teachers in the United Arab Emirates and Their Acceptance of the Inclusion of Students with Disabilities'.

${ }^{42}$ Gaad, 'Educating Children with Down's Syndrome in the United Arab Emirates'.

${ }^{43}$ Chris Forlin, Graham Douglas and John Hattie, 'Inclusive Practices: How Accepting are Teachers?', International Journal of Disability, Development and Education 43, no. 2 (1996), 119-33. 
${ }^{44}$ Alboro and Gaad, 'Employment of Young Adults with Disabilities in Dubai'.

${ }^{45}$ Crabtree, 'Maternal Perceptions of Care-Giving of Children with Developmental Disabilities in the United Arab Emirates'.

${ }^{46}$ Gaad, 'Educating Children with Down's Syndrome in the United Arab Emirates'.

${ }^{47}$ Muhammad Asad, Islam at the Crossroads (Kuala Lumpur: The Other Press, 1934/1999), 21.

${ }^{48}$ Sharon N. Barnatt and Venta Kabzems, 'Zimbabwean Teachers' Attitudes Towards the Integration of Pupils with Disabilities into Regular Classrooms', International Journal of Disability, Development and Edication 39, no. 2 (1992), 135-46.

${ }^{49}$ Majid Turmusani, 'Disabled Women in Islam', Journal of Religion, Disability \& Health 5, no. 2 (2001), 7385.

${ }^{50} \mathrm{Sa}$ ' dī Abū Jayb, Al-Muw 'awwaq qa al-mujtama 'fi al-shari 'a al-islamiyya (Damascus and Beirut: Dar alFikr al- Mu 'asir and Dar al-Fikr, 1402/1982), cited in Mohammed Ghaly, Islam and Disability: Perspectives in Theology and Jurisprudence (London: Routledge, 2010), 21.

${ }^{51}$ Ibid

${ }^{52}$ Ghaly, Islam and Disability.

${ }^{53}$ Sara Scalenghe, Disability in the Ottoman Arab World, 1500-1800 (New York: Cambridge

University Press, 2014).

${ }^{54}$ Ibid

${ }^{55}$ Sarah Pink et al., Digital Ethnography: Principles and Practice (London: Sage, 2016).

${ }^{56}$ Karen O'Reilly, Ethnographic Methods (London: Routledge, 2005).

${ }^{57}$ Martyn Hammersley and Paul Atkinson, Ethnography: Principles in Practice, 3rd ed. (New York: Routledge, 2007), 137.

${ }^{58}$ Christine Hine, Virtual Ethnography (London: Sage, 2000).

${ }^{59}$ Steve Woolgar, 'Technologies as Cultural Artefacts', in William H. Dutton (ed.), Information and

Communication Technologies: Vision and Realities (Oxford: Oxford University Press, 1996).

${ }^{60}$ Manuel Castells, The Rise of the Network Society (Oxford: Blackwell, 1996), 30.

${ }^{61}$ Christine Hine, The Internet: Understanding Qualitative Research (Oxford: Oxford University Press, 2013).

${ }^{62}$ Hine, Virtual Ethnography.

${ }^{63}$ Ibid.

${ }^{64}$ Daniel Miller and Heather A. Horst, 'The Digital and the Human: A Prospectus for Digital Anthropology', in

Heather A. Horst and Daniel Miller (eds), Digital Anthropology (London: Berg, 2012), 3-36.

${ }^{65}$ Ibid

${ }^{66}$ Hine, Virtual Ethnography, 30.

${ }^{67}$ Sarah Pink et al., Digital Ethnography.

${ }^{68}$ Charles Soukup, 'The Postmodern Ethnographic Flaneur and the Study of Hyper-Mediated Everyday Life', Urban Studies 42, no. 2 (2013), 226-54.

${ }^{69}$ Larissa Hjorth and Kyoung-hwa Yonnie Kim, 'The Mourning After: A Case Study of Social Media in the

3.11 Earthquake Disaster in Japan', Television \& New Media 12, no. 6 (2011), 552-9.

${ }^{70}$ Internet World Stats, 'Internet Users in the Middle East, June 2016',

http://www.internetworldstats.com/stats5.htm (accessed 7 August 2016).

${ }^{71}$ Alice E. Marwick and danah boyd, 'I Tweet Honestly, I Tweet Passionately: Twitter Users, Context Collapse, and the Imagined Audience', New Media \& Society 13, no. 1 (2011), 114-33

${ }^{72}$ Ibid., 115.

${ }^{73}$ Michel Foucault, Discipline and Punish (Hammondsworth: Penguin, 1991).

${ }^{74}$ James Ryan, 'Observing and Normalizing: Foucault, Discipline, and Inequality in Schooling: Big Brother is

Watching You', Journal of Educational Thought 25, no. 2 (1991), 104-19.

${ }^{75}$ Foucault, Discipline and Punish.

${ }^{76}$ Ibid., 173

${ }^{77}$ Lisa Downing, The Cambridge Introduction to Michel Foucault (Cambridge: Cambridge University Press, 2008), 82.

${ }_{78}^{70}$ James Ryan, 'Observing and Normalizing'

${ }^{79}$ Foucault, Discipline and Punish.

${ }^{80}$ Ibid., 298.

${ }^{81}$ Michel Foucault, 'Technologies of the Self', in Martin L. Gutman and Patrick H. Hutton (eds), Technologies of the Self: A Seminar with Michel Foucault (Amherst: The University of Massachusetts, 1988), 16-49.

${ }^{82}$ Michel Foucault, The History of Sexuality, Vol. 1: The Will to Knowledge (London: Penguin, 1990); Michel Foucault, The History of Sexuality, Vol. 3: The Care of the Self (London: Penguin, 1990); and Michel Foucault, The History of Sexuality, Vol. 2: The Use of Pleasure (London: Penguin, 1992).

${ }^{83}$ Michel Foucault, 'The Subject and Power', Critical Inquiry 8, no. 4 (1982), 208.

${ }^{84}$ Paul Rabinow, The Foucault Reader: An Introduction to Foucault's Thought (London: Penguin, 1984), 8. 
${ }^{85}$ Maryam Mohammad Khalfan Al Roumi, 'UAE Ratifies UN Convention on Rights of People with Disabilities', Gulf News, 10 February 2008, http://www.gulfnews.com/news/uae/general/uae-ratifies-unconvention-on-rights-of-people-with-disabilities-1.83978 (accessed 27 January 2017).

${ }^{86}$ Ramola Talwar Badam, 'UAE Advocacy Group to Tackle Problems Faced By People With Disabilities', National, 20 December 2015, http://www.thenational.ae/uae/health/uaeadvocacy-group-to-tackle-problemsfaced-by-people-with-disabilities (accessed 27 January 2017).

${ }^{87}$ My Community, 'Strategy', http://www.mycommunitydubai.com/page/strategy (accessed 27 January 2017).

${ }^{88}$ Foucualt, The History of Sexuality: Vol. 1.

${ }^{89}$ Emirates News Agency, 'UAE to Bid for the 2024 Olympic Games', WAM Dubai, 29 July 2011, http://www.wam.ae/en/news/emirates-international/1395228991653.html (accessed 25 August 2016); Ola Salem, 'Dubai’s Olympic Wait Will Be Worth It, Officials Say', National, 1 August 2011, http://www.thenational.ae/news/uae-news/dubais-olympic-wait-will-be-worthit-officials-say (accessed 25 August 2016).

${ }^{90}$ Hamdan Bin Mohammed Heritage Centre, 'Fazza Championships for the Disabled', http://hhc.gov.ae/en/championship/fazza-championships-for-the-disabled/ (accessed 25 August 2016). ${ }^{91}$ Mahfoud Amara, 'Sport and Political Leaders in the Arab World', Histoire@Politique 2, no.23 (2014), 142 53 .

${ }^{92}$ Davidson, The United Arab Emirates.

${ }^{93}$ Sarah Hopkyns, 'The Effects of Global English on Culture and Identity in the UAE: A Double-Edged Sword', Learning and Teaching in Higher Education: Gulf Perspectives 11, no. 2 (2014), 1-17.

${ }^{94}$ Ibid

${ }^{95}$ Business in Qatar and Beyond, 'UAE's Population - By Nationality', 12 April 2015, http://www.bqmagazine.com/economy/socioeconomics/2015/04/uae-population-by-nationality (accessed 10 September 2016). ${ }^{96}$ Amara, Sport Politics and Society in the Arab World.

${ }^{97}$ Susan Goodman, Spirit of Stoke Mandeville: The Story of Ludwig Guttmann; and Joan Scruton, Stoke Mandeville: Road to the Paralympics (London: Collins, 1986).

${ }^{98}$ Foucault, Discipline and Punish .

${ }^{99}$ United Arab National Paralympic Committee, 'Objectives', http://www.uaenpc.ae.

${ }^{100}$ Gaad, 'The Social and Educational Impacts of the First National Down Syndrome Support Group in the UAE'.

${ }^{101}$ Carla Filomena Silva and P. David Howe, 'The (In)Validity of Supercrip Representation of Paralympian Athletes', Journal of Sport and Social Issues 36, no. 2 (2012), 174-94.

${ }^{102}$ Ramola Talwa Badam, 'Dubai Aiming to Be One of World's Most Disabled Friendly Cities By 2020', National, 13 April 2016, http://www.thenational.ae/uae/health/20160413/dubaiaiming-to-be-one-of-worldsmost-disabled-friendly-cities-by-2020 (accessed 15 September 2016).

${ }^{103}$ Alboro and Gaad, 'Employment of Young Adults with Disabilities in Dubai'; Alghazo and Gaad, 'General Education Teachers in the United Arab Emirates and Their Acceptance of the Inclusion of Students with Disabilities'; Crabtree, 'Maternal Perceptions of Care-Giving of Children with Developmental Disabilities in the United Arab Emirates'; Gaad,'Educating Children with Down's Syndrome in the United Arab Emirates'; Gaad, 'Cross-Cultural Perspectives On the Effect of Cultural Attitudes Towards Inclusion for Children with Intellectual Disabilities'; and Gaad, 'The Social and Educational Impacts of the First National Down Syndrome Support Group in the UAE'.

${ }^{104}$ Gaad, 'The Social and Educational Impacts of the First National Down Syndrome Support Group in the UAE'.

${ }^{105} \mathrm{Ibid}$

${ }^{106}$ Hine, Virtual Ethnography.

${ }^{107}$ Mark J. McLelland, 'Virtual Ethnography: Using the Internet to Study Gay Culture in Japan', Sexualities 5, no. 4 (2002), 387-406.

${ }^{108}$ Hine, Virtual Ethnography.

${ }^{109}$ Lindsay Van Gelder, 'The Strange Case of the Electronic Lover', in Charles E. Dunlop and Rob King (eds), Computerization and Controversy: Value Conflicts and Social Choices (New York: Boston Academic Press, 1991); and Allucquere Rosanne Stone, The War of Desire and Technology at the Close of the Mechanical Age (Cambridge, MA: MIT Press, 1996), 364-75.

${ }^{110}$ Henry, Amara and Al-Tauqi, 'Sport, Arab Nationalism and the Pan-Arab Games'. 